\title{
Educação Infantil e complexidade: um panorama das pesquisas brasileiras
}

\author{
Early childhood education and complexity: an overview of brazilian research \\ Complejidad y educación de la primera infancia: una visión general de la investigación brasileña
}

Recebido: 31/10/2021 | Revisado: 08/11/2021 | Aceito: 11/11/2021 | Publicado: 20/11/2021

Cléo Mann

ORCID: https://orcid.org/0000-0001-8991-9491

Pontifícia Universidade Católica do Paraná, Brasil E-mail: cleomann7@gmail.com

Mariana da Rocha Carvalho

ORCID: https://orcid.org/0000-0001-9085-7662

Pontifícia Universidade Católica do Paraná, Brasil E-mail: carvalho.mariana@pucpr.edu.br

Daniele Saheb

ORCID: https://orcid.org/0000-0003-1317-6622

Pontifícia Universidade Católica do Paraná, Brasil

E-mail: danisaheb@yahoo.com.br

\begin{abstract}
Resumo
O presente estudo se caracteriza como uma pesquisa do tipo Estado da Arte, e teve como intenção compreender como se dá a produção do conhecimento na área da Educação Infantil, sob a ótica da complexidade, a partir de pesquisas já realizadas, percebendo seus enfoques e perspectivas. Neste estudo foram associados os procedimentos metodológicos embasados nos passos propostos por Romanowski (2002) e a análise de dados se deu a partir de Franco (2005). Na primeira etapa da pesquisa foi realizado um levantamento de teses e dissertações na Biblioteca Digital Brasileira de Teses e Dissertações, que continham os descritores educação infantil e complexidade, resultando em 143 pesquisas. Após a aplicação dos critérios de inclusão e exclusão, o corpus de análise foi constituído por 09 pesquisas, que permitiram relacionar as etapas da pesquisa com utilização dos princípios da complexidade propostos por Morin (2003). A partir da análise de dados, ficou perceptível uma fragilidade e superficialidade das pesquisas na área, e a necessidade de aprofundar os estudos a respeito dessa temática.
\end{abstract}

Palavras-chave: Estado da arte; Complexidade; Educação Infantil.

\begin{abstract}
The present study is characterized as State-of-the-art research, and had the intention its goal is to understand how the production of knowledge in the area field of Early Childhood Education takes place, from the perspective of complexity, based on research already carried out, realizing its approaches and perspectives. In this study, the methodological procedures based on the steps proposed by Romanowski (2002) were associated and the data analysis that took place from Franco (2005). In the first stage of the research, a survey of theses and dissertations was carried out in the Brazilian Digital Library of Theses and Dissertations, which contained the descriptors early childhood education and complexity, resulting in 143 researches. After applying the inclusion and exclusion criteria, the corpus of analysis consisted of 09 researches, which allowed relating the research stages using the complexity principles proposed by Morin (2003). From the data analysis, it was noticeable a weakness and superficiality of the researches in the area, and the need to deepen the studies about this theme.
\end{abstract}

Keywords: State of the art; Complexity; Child education.

\section{Resumen}

El presente estudio se caracteriza por ser una investigación de estado del arte, y su intención fue comprender como se produce el conocimiento en el área de la Educación Infantil, desde la perspectiva de la complejidad, a partir de investigaciones ya realizadas, realizando sus enfoques y perspectivas. En este estudio se asociaron los procedimientos metodológicos basados en los pasos propuestos por Romanowski (2002) y el análisis de los datos empezaron a partir de Franco (2005). En la primera etapa de la investigación, se realizó un levantamiento de tesis y disertaciones en la Biblioteca Digital Brasileña de Tesis y Disertaciones, que contenía los descriptores educación y complejidad de la primera infancia, resultando en 143 investigaciones. Luego de aplicar los criterios de inclusión y exclusión, el corpus de análisis constó de 09 investigaciones, lo que permitió relacionar las etapas de investigación utilizando los principios de complejidad propuestos por Morin (2003). A partir del análisis de los datos, se notó una debilidad y superficialidad de las investigaciones en el área, y la necesidad de profundizar los estudios sobre este tema.

Palabras clave: Estado del arte; Complejidad; Educación Infantil. 


\section{Introdução}

A pesquisa do tipo Estado da Arte permite realizarmos um mapeamento das pesquisas já realizadas sobre determinada temática, possibilitando o conhecimento e reconhecimento dos estudos já realizados com determinado enfoque. Sendo assim, além de se posicionar sobre o que os estudos vêm tratando sobre seu objeto de estudo, pode-se obter embasamento para a realização da sua pesquisa.

A educação infantil é a primeira etapa da Educação Básica, e atende crianças de zero a cinco anos de idade. Sendo um direito de todas as crianças, é obrigatório para crianças a partir de quatro anos.

Rodrigues e Boer (2019, p.3) ressalta que o desenvolvimento de pesquisas na área da Educação Infantil torna-se importante, uma vez que, aos poucos, vai suprindo as lacunas acerca desta etapa da educação, possibilitando reflexões sobre as ações docentes. Esta etapa entende o cuidado como indissociável do processo pedagógico, educar e cuidar andam lado a lado, e tem por objetivo ampliar as experiências da criança, colocando-a como protagonista, e buscando desenvolver novas habilidades e competências, incluindo-a no processo de socialização, trabalhando a autonomia e a comunicação (BNCC, 2017).

O pensamento complexo diz respeito à existência de relações lógicas entre diversas dimensões, não podendo fragmentar ou isolar um objeto, uma vez que, tudo é resultado de múltiplas interações (Moraes \& Navas, 2010). Morin (2003, p.15) traz que Complexus significa o que se tece junto, deste modo o pensamento complexo, busca distinguir e ligar as dimensões, não separando-as pois entende-se que tudo está conectado. O pensamento complexo é contextualizado e global, busca unir, compreendendo o desafio da incerteza.

Nesse sentido, a lógica que condiciona a produção de conhecimento é caracterizada pelo recorte arbitrário da realidade, isto é, seleciona-se determinados dados "significativos", rejeita-se, por consequência, os dados "insignificantes", em seguida, os dados coletados são separados e hierarquizados a partir de operações lógicoformais "aceitas" pela comunidade científica. (Lemos, et al, 2019, p. 7 e 8).

Desse modo, analisar a presença da complexidade na Educação Infantil contribui para compreendermos o contexto dos estudos na área, e permite refletir sobre a importância de aprofundá-los considerando as contribuições que a complexidade pode trazer para o processo de ensino aprendizagem e para a prática pedagógica na Educação Infantil. Pensando na relação dessas duas temáticas como a

(...) única esperança no despertar da consciência e na força do amor. Ele nos faz entender que viver é uma navegação num oceano de incertezas com algumas ilhas de certezas para se orientar e se abastecer. Ele nos estimula a decidir e agir no incerto. (Morin, 2020, p. 101).

\section{Encaminhamento Metodológico}

Este artigo tem como intenção compreender como se dá a produção do conhecimento na área da Educação Infantil, sob a ótica da complexidade, em teses e dissertações. Podendo não somente chegar em um resultado quantitativo, mas também analisá-lo, categoricamente percebendo seus enfoques e perspectivas.

O interesse por pesquisas que abordam "estado da arte" deriva da abrangência desses estudos para apontar caminhos que vêm sendo tomados e aspectos que são abordados em detrimento de outros. A realização destes balanços possibilita contribuir com a organização e análise na definição de um campo, uma área, além de indicar possíveis contribuições da pesquisa para com as rupturas sociais. A análise do campo investigativo é fundamental neste tempo de intensas mudanças associadas aos avanços crescentes da ciência e da tecnologia. (Romanowski \& Ens, 2006, p.38 e 39).

Esse tipo de pesquisa pode trazer consideráveis contribuições na constituição do campo teórico de determinada 
temática, uma vez que através da análise torna-se possível verificar o aporte teórico, as restrições sobre o campo e suas lacunas, identificando as necessidades de pesquisa e contribuições inovadoras para aquela área do conhecimento. Além disso, justificam-se por assegurar uma visão geral do que já foi produzido na área e com a sistematização, também é possível aos futuros pesquisadores, perceber a evolução das pesquisas, características, focos e lacunas existentes. (Romanowski \& Ens, 2006).

Ferreira (2002, p. 258) define as pesquisas deste caráter com a função de mapear e discutir as produções acadêmicas de determinado tempo e lugar, de diversos campos do conhecimento, buscando oferecer um panorama com os principais aspectos e dimensões que vêm sendo discutidos e privilegiados.

Como qualquer pesquisa, carece de uma metodologia bem estruturada e passos específicos que devem ser pensados e seguidos. Para isso optou-se por utilizar os passos propostos por Romanowski (2002), explanando que para a realização de pesquisas do tipo estado da arte é necessário os procedimentos, estruturados na Figura 1:

Figura 1 - Encaminhamento metodológico a partir de Romanowski (2002).

\section{ENCAMINHAMENTO METODOLÓGICO}

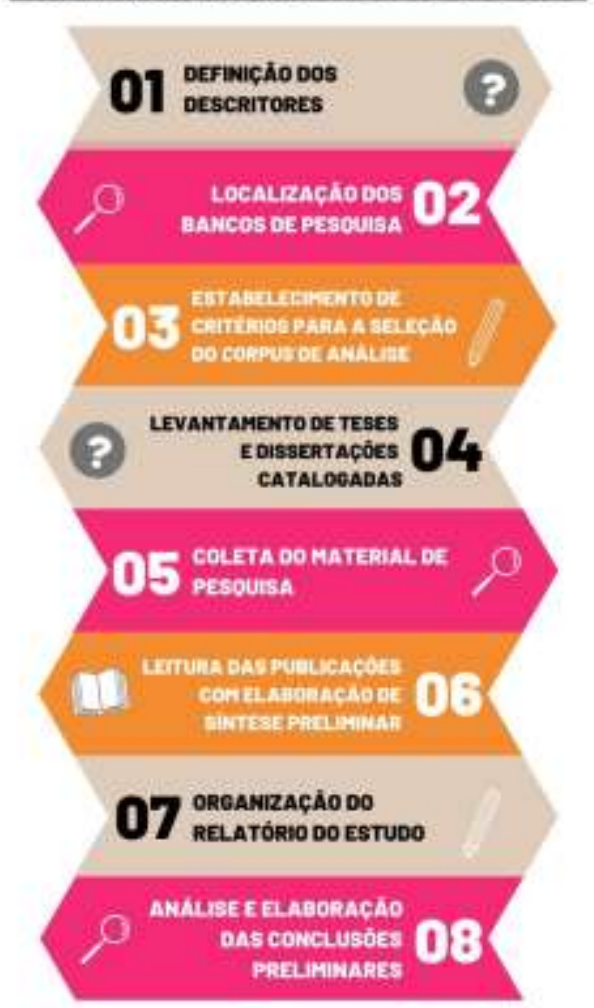

Fonte: Autores (2021).

O foco principal desta pesquisa é identificar quais as tendências, recorrências e lacunas nas pesquisas que articulam a teoria da complexidade de Morin e educação infantil. Para tal, foram selecionados os descritores 'educação infantil' AND complexidade.

A fim de validar a existência de revisão sistemática sobre a temática, foi realizada uma busca na Campbell Collaboration, uma rede internacional de pesquisa em ciências sociais. A busca se deu por revisões sistemáticas já existentes com os termos: "Complexity theory" (0 resultados); Morin (0 resultados); "Preschool education" (5 resultados). No entanto, dos 5 artigos encontrados na plataforma nenhum deles abordava a temática da pesquisa.

Ao realizar a busca, iniciou-se em alguns banco de dados de artigos como a Scielo e Eric. No entanto, os resultados 
eram poucos (menos de 20), o que não possibilita o estudo aprofundado acerca das temáticas. É importante ressaltar que foi realizada também a busca do descritor educação infantil sem aspas, mas ainda assim o resultado não foi suficiente e identificamos que algumas pesquisas não eram desse nível de ensino.

Sendo assim, ficou definido que a busca desse estado da arte seria na Biblioteca Digital Brasileira de Teses e Dissertações (BDTD) que integra em um único sistema, o catálogo de teses e dissertações existentes no país. Ao realizar o primeiro levantamento de dados, foi selecionada a opção ‘busca avançada' e utilizando os descritores "educação infantil” AND complexidade, optou-se por buscar nos resumos em português e não somente nos títulos, sem a definição de um marco temporal. Nessa busca, foram encontrados inicialmente 143 resultados, exportados para uma planilha do Excel.

O primeiro critério de exclusão, seriam as pesquisas de 2021, já que podem ser inseridos mais trabalhos até dezembro. Porém, nenhum foi excluído já que os mais recentes correspondiam ao ano de 2020. O critério seguinte, foi retirar os trabalhos duplicados a partir da leitura dos títulos e, com isso, foram excluídos 2 trabalhos.

$\mathrm{Na}$ etapa seguinte foram organizados todos os documentos com o resumo, aqueles que a exportação não incluiu o resumo, o processo foi realizado de modo manual. Nesta etapa surgiram alguns desafios. 17 documentos não estavam com o link disponível e, mesmo buscando nas bibliotecas originais das universidades, não foram localizadas e, ainda, 01 que não possuía o resumo disponibilizado.

A próxima etapa foi realizar a leitura dos resumos e identificar quais pesquisas tinham os descritores educação infantil e complexidade, já que como algumas bibliotecas têm a opção de leitura do trabalho na íntegra no link disponibilizado na BDTD, caso os descritores sejam citados na dissertação ou tese como um todo, também seriam selecionados na busca. Com isso, 62 pesquisas não atendiam ao critério e não foram incluídas. Vale a ressalva aqui, que foram excluídas aquelas que não tinham o descritor complexidade e nem semelhantes, como complexo ou complexa.

Ainda na leitura dos resumos, foi possível identificar que, apesar de conter o descritor complexidade, ou semelhantes, alguns não se referem à teoria da complexidade e sim, trazem o descritor como sinônimo de algo difícil, de alta complexidade. Nessa leitura minuciosa, foram excluídos 49 trabalhos.

Por fim, o último critério de exclusão foram as pesquisas que, apesar de atenderem aos critérios anteriores, não correspondiam à complexidade de Morin, autor principal de nossa fundamentação teórica e tal ponto, poderia causar divergências na análise. Nessa etapa foram excluídos 3 trabalhos. Sendo assim, o presente estado da arte apresentará a contribuição de 9 teses e dissertações, que contemplam os critérios definidos e explicados anteriormente. Para melhor visualização da seleção do corpus do Estado da Arte, apresentam-se na sequência a Tabela 1: 
Tabela 1 - Processo de seleção do corpus de análise (BDTD).

\begin{tabular}{l|c|c}
\hline \multicolumn{1}{c|}{ Seleção corpus de análise } & Op & Quantidade \\
\hline Descritores: complexidade AND educação infantil & + & 143 \\
\hline Total a partir das palavras-chaves: & & $\mathbf{1 4 3}$ \\
\hline Duplicados & - & 2 \\
\hline Total (excluídos os duplicados): & $=$ & $\mathbf{1 4 1}$ \\
\hline Critérios de Exclusão: & - & 0 \\
$\begin{array}{l}\text { Trabalhos de 2021 } \\
\text { Não tinham a palavra "complexidade" ou “educação } \\
\text { infantil” título, resumo e/ou palavras-chaves }\end{array}$ & - & 62 \\
$\begin{array}{l}\text { Utilizavam a palavra complexidade em outros } \\
\text { contextos }\end{array}$ & - & 49 \\
$\begin{array}{l}\text { Não tinham como fundamentação a complexidade de } \\
\text { Morin }\end{array}$ & - & 3 \\
\hline Total após a aplicação dos critérios de exclusão: & $=$ & $\mathbf{2 7}$ \\
\hline Arquivo indisponível & - & 17 \\
$\begin{array}{l}\text { Resumo indisponível } \\
\text { Total (excluídos os indisponíveis): }\end{array}$ & - & 1 \\
\hline Total de arquivos: (corpus de análise): & $=$ & $\mathbf{9}$ \\
\hline
\end{tabular}

Fonte: Autores (2021).

Sendo assim, foram analisadas 9 pesquisas, a partir da análise de conteúdo proposta Franco (2005), em uma nova planilha no Excel. A partir da leitura dos resumos, foram identificadas as temáticas e com elas a elaboração de indicadores proposta pela autora.

Na sequência, foram definidas as categorias a priori que são predeterminadas em função da busca a uma resposta específica (Franco, 2005), acerca do uso da complexidade nas teses e dissertações que constituem o corpus de análise. Tais categorias foram selecionadas a partir dos princípios da complexidade, contudo, ficou perceptível que, somente com a leitura dos resumos não seria possível identificá-los e sendo assim, foram selecionados trechos das pesquisas que mencionam a complexidade ou o pensamento complexo.

A partir deles, foi realizada a categorização e, na sequência, a interpretação e tratamento dos dados obtidos, que por sua vez, serão explanados na seção a seguir.

\section{Resultados e Discussão}

Logo de imediato se percebe que a quantidade de pesquisas chama a atenção, por ser um número baixo, e isso justifica a importância de aprofundamento nessa área, relacionando a Educação Infantil com complexidade. Outro ponto que chama a atenção são os anos de publicação, sendo o primeiro publicado em 2007, dois em 2010, um em 2011, 2013 e 2014, dois em 2016 e somente um em 2017.

A seguir teremos a Tabela 2, que representa a relação dos trabalhos selecionados, por regiões do país. Com a análise desta, destaca-se o fato do Nordeste ter três publicações, e não ter nenhuma na região Centro-Oeste. Considerando que a complexidade tem como visão do sujeito como um todo, um ser integral, o que vai de encontro com a DCNEI (2010), que em seu artigo $4^{\circ}$, define a criança como sujeito histórico, dotado de direitos, que constrói sua identidade nas suas relações e interações, produzindo cultura, ressaltamos a importância de ampliar as produções na área, uma vez que devemos ver a criança 
como um todo, ativa no seu processo de ensino aprendizagem.

Tabela 2 - Relação de pesquisas por IES e regiões do país.

\begin{tabular}{lllcc}
\hline \multicolumn{1}{c}{ Regiões } & Instituição & Teses & Dissertações & $\begin{array}{c}\text { Total de } \\
\text { documentos }\end{array}$ \\
\hline \multirow{2}{*}{ Nordeste } & UFRN & 1 & 1 & 2 \\
& UFMA & 0 & 1 & 1 \\
\hline \multirow{2}{*}{ Norte } & UFRPE & 0 & 1 & 1 \\
\hline \multirow{2}{*}{ Sudeste } & UFT & 1 & 0 & 1 \\
& PUC_RIO & 0 & 1 & 1 \\
\hline \multirow{2}{*}{ Sul } & UNESP & 1 & 0 & 1 \\
\hline \multirow{2}{*}{} & METODISTA & 0 & 1 & $\mathbf{9}$ \\
\hline
\end{tabular}

Fonte: Autores (2021).

Para fazer a análise foram definidos como categorias os princípios propostos por Morin (2003, p.15), sendo princípios complementares e interdependentes que orientam essa forma de pensar: São eles: princípio sistêmico ou organizacional, princípio hologramático, princípio do anel recursivo, princípio de auto-eco-organização, princípio dialógico, princípio da reintegração do conceptor e o princípio do tetragrama organizacional.

O princípio sistêmico ou organizacional diz respeito ao conhecimento do todo e das partes, e como estão ligados, sendo impossível conhecer o todo sem conhecer as partes, e vice-versa. Sendo o todo mais do que a soma das partes, e a compreensão do todo produzindo novas considerações às partes. O princípio hologramático, como o próprio nome diz, evidencia o paradoxo complexo, no qual não somente a parte está no todo, mas o todo está na parte.

O princípio do anel recursivo diz respeito aos processos necessários para a produção do próprio processo, superando a noção de regulação com a de autoprodução e auto-organização, é um anel gerador, como por exemplo: indivíduo- sociedade. Princípio da auto-eco-organização traz a ideia de autonomia e dependência, uma vez que diz respeito à organização individual e do meio, e suas mútuas influências, e o disparador para o mesmo, é a desordem.

O princípio dialógico que vem da ideia de antagônico, une duas noções contrárias, mas dependentes, indissociáveis, como a ideia de ordem e desordem. O princípio da reintegração do conceptor, opera sobre a complexidade das teorias científicas, de que todo conhecimento é uma reconstrução realizada por determinado ser, inserido em uma cultura e tempo específico. Por fim, o tetragrama organizacional, que envolve as relações de ordem, desordem, organização e interação.

Feito isso, percebeu-se que somente com a leitura do resumo não seria possível identificar quais são os princípios que aparecem em cada um dos trabalhos, e por isso, foi feito um levantamento acerca da leitura das teses e dissertações selecionadas, identificando quais os princípios mencionados ou a que se fazia referência e em qual etapa da pesquisa isso ocorreu. As quantidades identificadas podem ser melhor percebidas na Tabela 3, a seguir. 
Tabela 3 - Temáticas entrelaçadas a partir dos princípios da Complexidade.

\begin{tabular}{llc}
\hline Área & Categorias & Quantidade \\
\hline & Dialógica (D) & 9 \\
& Hologramático (H) & 21 \\
& Sistêmico-organizacional (SO) & 17 \\
Princípios da complexidade & Reintegração do conceptor (RC) & 2 \\
& Auto-eco-organização (AEO) & 4 \\
& Tetragrama (T) & 10 \\
& Recursivo (R) & 2 \\
\hline
\end{tabular}

Fonte: Autores (2021).

As categorias acima, foram identificadas a partir das definições dos princípios citados anteriormente de Morin e com isso, percebe-se que os mais citados foram o princípio Hologramático (H) e o Sistêmico-organizacional (SO), tal aspecto tem extrema relevância, pois partimos do ponto que todos os princípios são complementares e interdependentes, portanto em qualquer pesquisa que se tenha a complexidade como temática, é importante considerar as relações entre eles e considerar no discurso todas as suas concepções.

Ao categorizar as teses e dissertações com os princípios, pode-se identificar uma fragilidade ou superficialidade nas pesquisas no que diz respeito à complexidade. Tendo em vista que, mesmo que os pesquisadores compreendam a necessidade de aprofundamento desses princípios, não se atentaram a detalhar isso nas suas pesquisas, o que pode indicar uma lacuna na área.

Como foi possível visualizar, o princípio da reintegração do conceptor e o recursivo foram os menos citados, seguidos do princípio da auto-eco-organização e o princípio dialógico. Tal ponto precisa ser destacado tendo em vista que, principalmente os dois últimos citados estão diretamente relacionados com a concepção de criança, prevista na BNCC (2017), que assegura que a criança precisa ser vista como

ser que observa, questiona, levanta hipóteses, conclui, faz julgamentos e assimila valores e que constrói conhecimentos e se apropria do conhecimento sistematizado por meio da ação e nas interações com o mundo físico e social não deve resultar no confinamento dessas aprendizagens a um processo de desenvolvimento natural ou espontâneo. Ao contrário, impõe a necessidade de imprimir intencionalidade educativa às práticas pedagógicas na Educação Infantil, tanto na creche quanto na pré-escola. (Brasil, 2017, p. 38).

Se faz necessário ressaltar que mesmo a BNCC sendo de 2017 e a maioria das pesquisas aqui analisadas publicadas antes desta data, tais pontos dialogam com o respeito à dignidade de criança como pessoa humana e o "atendimento ao direito da criança na sua integralidade" (Brasil, 2010, p. 93), que já estavam previstos nas Diretrizes Curriculares Nacionais em 2010.

Identifica-se aqui, que o uso dos princípios da complexidade nas pesquisas que constituem o corpus de análise, estão muito voltados aos princípios hologramático e sistêmico-organizacional que, estão conectados diretamente com a definição macro da complexidade de, "aquilo que é tecido junto" (Morin, 2017, p. 14) e a relação, indissociação e complementaridade entre o todo e as partes, as partes e o todo.

No entanto, é preciso ressaltar que, apesar de trazerem concepções importantíssimas ao estudo da complexidade, reduzir seu uso em uma pesquisa a essas definições, demonstra um sentido superficial ao que é estudado pelo autor norteador dessa pesquisa e a todos os outros princípios citados anteriormente.

A fim de auxiliar o leitor no mapeamento das pesquisas e quais os princípios foram mencionados ou feito referência, o Quadro 1 apresenta o panorama da interrelação das teses e dissertações com os princípios da complexidade. 
Quadro 1 - Panorama da interrelação das pesquisas com os princípios.

\begin{tabular}{|c|c|c|c|c|c|c|c|}
\hline \multirow{2}{*}{ Pesquisas } & \multicolumn{7}{|c|}{ Princípios da complexidade } \\
\hline & D & $\mathbf{H}$ & SO & RC & AEO & $\mathbf{T}$ & $\mathbf{R}$ \\
\hline OLIVEIRA, 2010 & & & $\mathrm{X}$ & & & & \\
\hline PEREIRA, 2014 & & $\mathrm{X}$ & $\mathrm{X}$ & & & & \\
\hline FLORES, 2007 & $\mathrm{X}$ & $\mathrm{X}$ & $\mathrm{X}$ & & & & \\
\hline TOLEDO, 2010 & $\mathrm{X}$ & $\mathrm{X}$ & $\mathrm{X}$ & & & $\mathrm{X}$ & \\
\hline PINHEIRO, 2011 & $\mathrm{X}$ & $\mathrm{X}$ & $\mathrm{X}$ & & $\mathrm{X}$ & $\mathrm{X}$ & $\mathrm{X}$ \\
\hline MARQUES, 2013 & & $\mathrm{X}$ & & & & & \\
\hline SOUZA, 2016 & & $\mathrm{X}$ & $\mathrm{X}$ & & & & \\
\hline AZEVEDO, 2016 & $\mathrm{X}$ & $\mathrm{X}$ & $\mathrm{X}$ & $\mathrm{X}$ & & & \\
\hline NASCIMENTO, 2017 & $\mathrm{X}$ & $\mathrm{X}$ & $\mathrm{X}$ & & $\mathrm{X}$ & $\mathrm{X}$ & $\mathrm{X}$ \\
\hline
\end{tabular}

Fonte: Autores (2021).

Outro ponto que é preciso destacar na presente análise, está para além do fato de quais princípios foram utilizados e sim para a quantidade do uso da complexidade e/ou pensamento complexo ao longo da escrita da tese e dissertação. É fato que a repetição do termo, por si só, não indicaria a superficialidade do uso da complexidade, no entanto considerando que a complexidade estava relacionada com a temática principal da pesquisa, algumas quantidades como 19 vezes de Marques (2013) e 16 vezes de Toledo (2010), trouxeram outro ponto para a reflexão: em qual etapa da pesquisa a complexidade foi relacionada com a temática principal da educação infantil?

O Gráfico 1, a seguir, apresenta a relação das 9 pesquisas com o uso da complexidade ou pensamento complexo na escrita da tese ou dissertação.

Gráfico 1 - Levantamento do uso da complexidade ou pensamento complexo nas pesquisas.

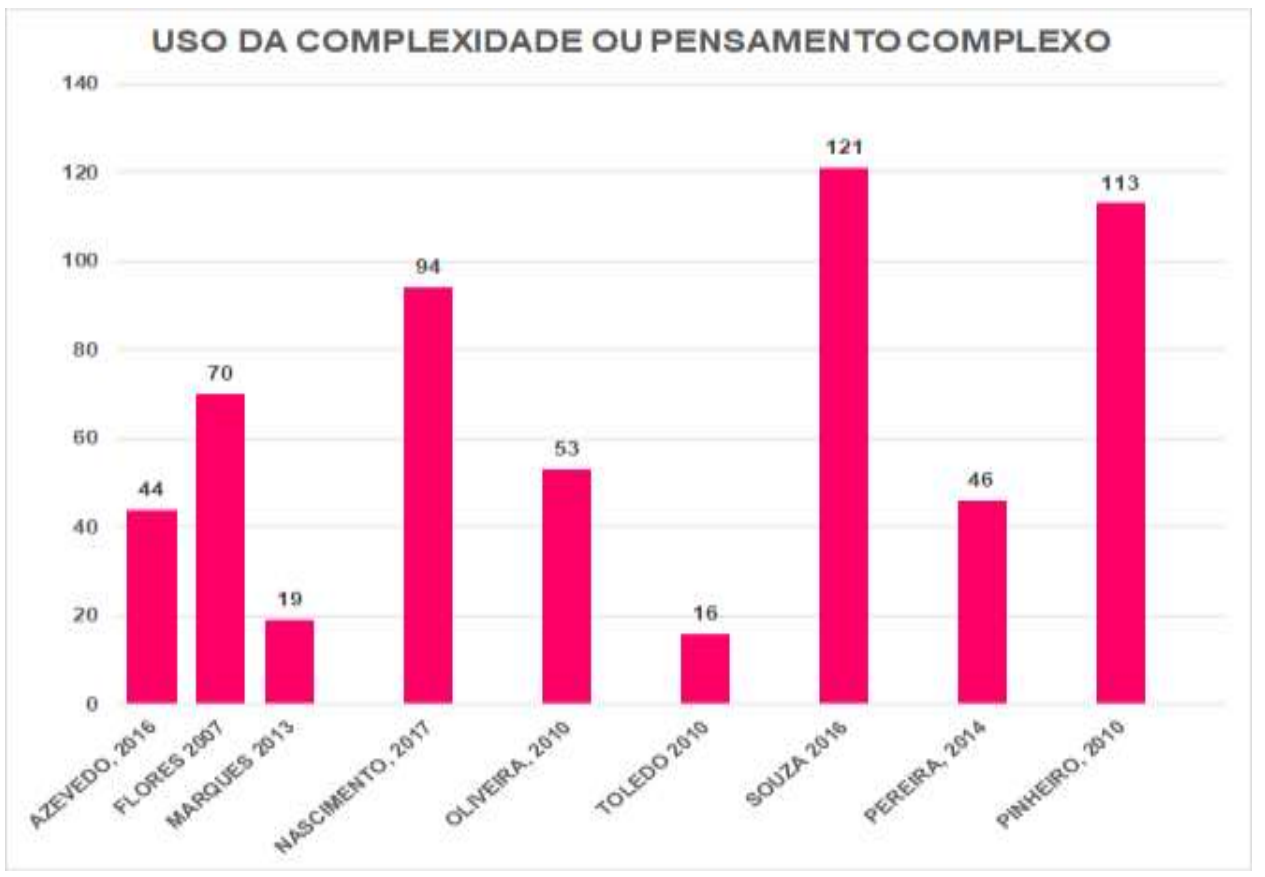

Fonte: Autores (2021). 
Com o intuito de responder a questão levantada anteriormente, se fez necessário identificar a relação entre o uso da complexidade nas teses e dissertações com a temática educação infantil, com a etapa da pesquisa em que foi mencionada. Para isso, foi realizada uma segunda categorização a partir das etapas da pesquisa.

A definição das categorias para tal, foram definidas a partir dos passos definidos do Flick (2013) no processo da pesquisa padronizada e não padronizada. Por se tratarem de passos muito detalhados, foram agrupados pelas autoras da seguinte forma: problema $(P)$, busca sistemática $(B S)$, metodologia $(M)$, análise de dados $(A D)$ e resultado $(R)$. Na sequência, a partir do levantamento feito anteriormente, foi realizada a categorização identificando as etapas da pesquisa. Tal relação pode ser observada com maior detalhe e mapeamento no Quadro 2, a seguir:

Quadro 2 - Panorama do uso da complexidade nas etapas da pesquisa propostas por Flick (2013).

\begin{tabular}{|l|c|c|c|c|c|}
\hline \multirow{2}{*}{\multicolumn{1}{|c|}{ Pesquisas }} & \multicolumn{5}{c|}{ Etapas da Pesquisa } \\
\cline { 2 - 6 } & P & BS & M & AD & R \\
\hline OLIVEIRA, 2010 & & $\mathrm{X}$ & & & \\
\hline PEREIRA, 2014 & $\mathrm{X}$ & $\mathrm{X}$ & $\mathrm{X}$ & $\mathrm{X}$ & $\mathrm{X}$ \\
\hline FLORES, 2007 & $\mathrm{X}$ & $\mathrm{X}$ & & & \\
\hline TOLEDO, 2010 & $\mathrm{X}$ & $\mathrm{X}$ & & & \\
\hline PINHEIRO, 2011 & & $\mathrm{X}$ & & & \\
\hline MARQUES, 2013 & & $\mathrm{X}$ & & & \\
\hline SOUZA, 2016 & & $\mathrm{X}$ & & $\mathrm{X}$ & $\mathrm{X}$ \\
\hline AZEVEDO, 2016 & & & & $\mathrm{X}$ & $\mathrm{X}$ \\
\hline NASCIMENTO, 2017 & & & & & \\
\hline
\end{tabular}

Fonte: Autores (2021).

Como pode-se perceber, é na busca sistemática que se concentra a maior relação com a complexidade nos trabalhos analisados, sendo que, é nessa parte da pesquisa que os autores buscam trazer contextos e embasamentos para o leitor. Contudo, tendo em vista as concepções que norteiam a complexidade, em pesquisas que a tenham como temática, espera-se que sua construção como teoria se dê em todas as etapas do processo, e não somente de forma isolada.

Para exemplificar tal apontamento, identifica-se que a tese de Flores (2007), não se restringiu ao uso da complexidade somente em uma etapa da pesquisa, mas buscou inseri-la em todos os momentos, demonstrando a construção do olhar dessa teoria para com sua pesquisa e trajetória. Também pode-se ressaltar a dissertação de Azevedo (2016), que trouxe as concepções da complexidade na busca sistemática e voltou a utilizá-las na análise de seus resultados, também dando um sentido significativo ao aprofundamento da teoria.

Tais pontos levantados convergem com a conjectura de que são necessárias mais pesquisas e maior aprofundamento acerca da relação com a complexidade e educação infantil. Outro ponto relevante a ser destacado aqui, está no fato de que talvez os pesquisadores mencionem a complexidade no resumo, mas não a tenham como principal fundamentação teórica, o que poderia justificar essa superficialidade em seu uso nas pesquisas.

A seguir, a figura 3, mostra a relação dos princípios com cada uma das temáticas abordadas nas pesquisas analisadas. As cores dos círculos permitem perceber quais princípios os autores utilizaram em suas teses e dissertações. Constata-se que 
alguns autores abordam apenas um princípio, enquanto outros abordam seis, sendo que nenhum aborda a totalidade apresentada (sete).

Figura 3 - Relação das temáticas das pesquisas com os princípios da complexidade.

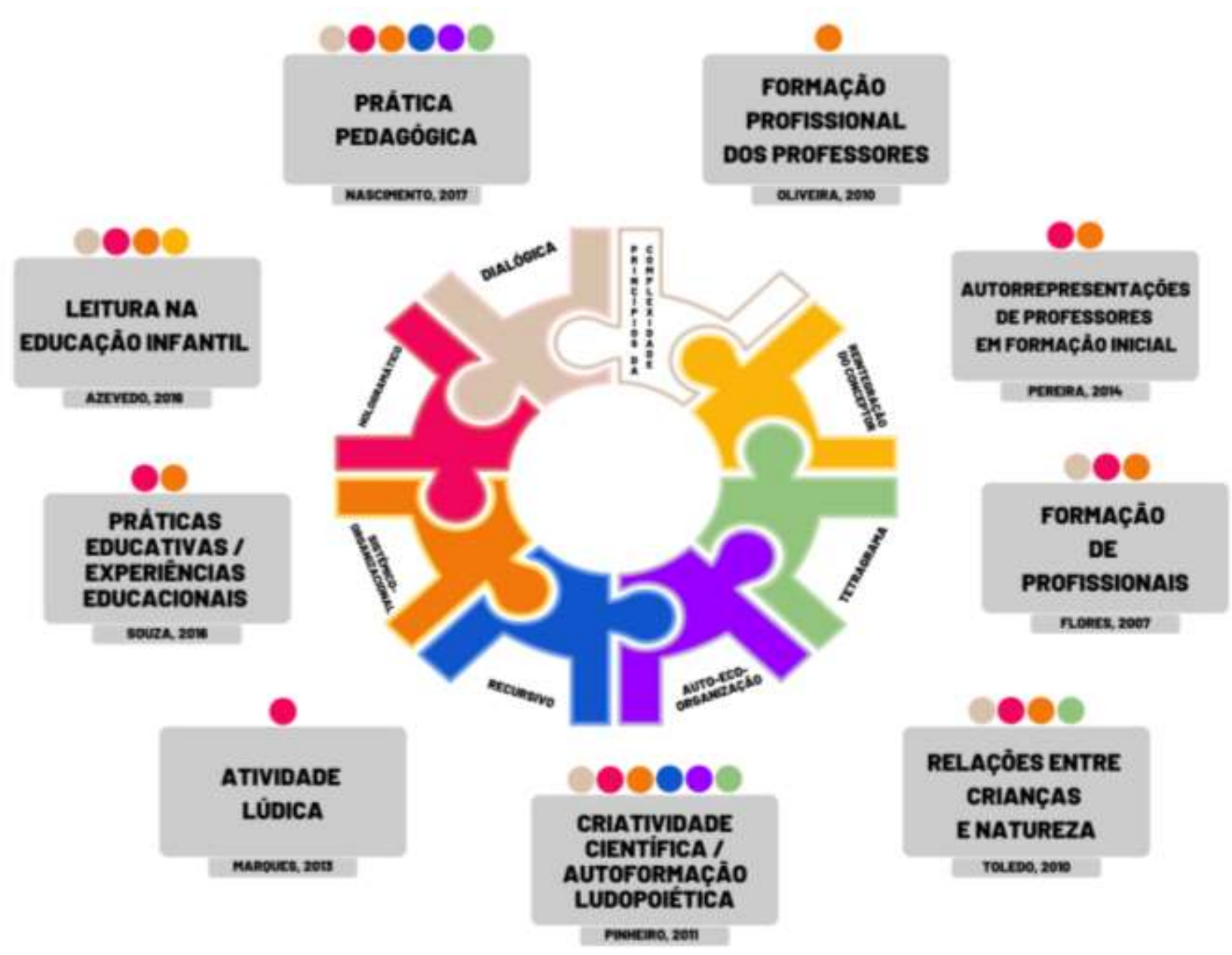

Fonte: Autores (2021).

Como foi possível identificar na Figura 3 é possível realizar um mapeamento das relações acerca das temáticas.

Três das pesquisas apresentam em suas temáticas a formação de professores, que foi o caso da dissertação de Oliveira (2010), intitulada Estudos da relação entre formação docente e desenvolvimento do pensamento: redimensionando os olhares, que tinha como objetivo compreender a relação entre a formação profissional dos professores dos anos iniciais do Ensino do Fundamental e o desenvolvimento do seu pensamento. A tese de Flores (2007), intitulada Movimento e complexidade na garantia do direito à Educação Infantil: um estudo sobre polÍticas públicas em Porto Alegre (1989-2004), que teve como objetivo investigar as polÍticas públicas para a Educação Infantil no municÍpio de Porto Alegre, implementadas no período entre 1989 e 2004, quando aconteceram quatro gestões consecutivas do Partido dos Trabalhadores na cidade. Além da tese de Pereira (2014) intitulada, Professores em formação inicial no gênero relatório de estágio supervisionado: um estudo em licenciaturas paraenses, que objetivou investigar autorrepresentações de professores em formação inicial.

Duas pesquisas tratam em suas temáticas sobre a prática docente, a dissertação de Nascimento (2017) (Boas) práticas na creche: miradas emergentes sobre a criança e a infância, aborda sobre prática pedagógica, e buscou investigar diferentes olhares sobre o conceito de (boas) práticas na creche a partir da narrativa da pesquisadora acerca de suas experiências 
formativas e com crianças pequenas e professoras. E a dissertação de Souza (2016), que traz a prática educativa, intitulada: Além da escola: reflexões teórico-metodológicas com base na análise de práticas educativas alternativas descobertas em áreas rurais da região de São Carlos São Paulo, que teve como objetivo estudar práticas educativas em de territórios rurais da região de São Carlos (SP).

Uma pesquisa com a temática de atividade lúdica, que foi a dissertação de Marques (2013), intitulada: a ludicidade e o simbolismo na infância: um estudo hermenêutico em uma brinquedoteca escolar do município de São Luís/MA, que teve como objetivo compreender as expressões simbólicas presentes nas atividades lúdicas desenvolvidas em uma brinquedoteca escolar municipal. E também apenas uma pesquisa tinha como tema a leitura na educação infantil, intitulada Leitura literária e transdisciplinaridade: uma ponte possível para os direitos humanos com crianças em sala de aula, escrita por Azevedo (2016).

A Tese de Pinheiro (2011) abordou a temática da criatividade científica, que foi intitulada: Dançando com gatos e pássaros: O movimento ecossistêmico da ludopoiese na educação infantil, a qual utilizou-se a metáfora da dança como uma possibilidade de estimular a criatividade cientí-fica.

Por fim, não menos importante, a dissertação intitulada children`s relations and conceptions with/of nature: Rio de Janeiro, de Toledo (2010) abordou a temática da criança e a natureza, a qual repensa as relações entre seres humanos e natureza, a partir das dimensões macro e micro, considerando o ambiente facilitador da construção das relações.

\section{Considerações Finais}

O estado da arte nos permite identificar, visualizar e categorizar elementos sobre determinada temática, podendo refletir sobre a produção científica em um área e tempo específicos, podendo auxiliar o pesquisador a conhecer o que já foi produzido em relação ao seu tema. Assim, esse artigo considera que existem um número consideravelmente baixo de pesquisas que tenham como objeto de estudo a educação infantil, relacionando-a com a complexidade proposta por Morin. Desse modo, tal dado necessita de olhares futuros, pois pode contribuir para a compreensão de sociedade, e ser uma ferramenta de reflexão para os docentes, interferindo na sua prática pedagógica.

Tendo em vista que na primeira busca foram encontrados 143 resultados, já se percebe a carência de estudos relacionados à complexidade, dentre eles somente 9 estavam relacionados à Complexidade como teoria proposta pelo autor em discussão. Outro ponto que reforça a necessidade de mais estudos na área, está no fato de que, ainda das 9 teses e dissertações analisadas, percebe-se uma fragilidade em relação aos princípios e superficialidade do uso da complexidade nas pesquisas relacionadas à educação infantil.

Assim, as investigações realizadas revelaram a existência de um número expressivamente baixo de pesquisas que relacionam a temática educação infantil com a complexidade de Morin. Com o presente mapeamento, abre-se um leque de possibilidades de aprofundamento a serem estudados e discutidos em futuras pesquisas, relacionando essas duas temáticas.

\section{Referências}

Azevêdo, N. M. S. (2016). Leitura literária e transdisciplinaridade: uma ponte possível para os direitos humanos com crianças em sala de aula. Dissertação (Programa de Pós-Graduação Associado em Educação, Culturas e Identidades) - Universidade Federal Rural de Pernambuco. http://www.tede2.ufrpe.br:8080/tede2/handle/tede2/5304.

Brasil (2017). BNCC - Base Nacional Comum Curricular. Brasília: MEC, SEB. https://bit.ly/35RdgQY.

Ferreira, N. S. A. (2002). As pesquisas denominadas "estado da arte". Educação \& sociedade, v. 23, n. 79, p. $257-272$.

Flick, U. (2013). Uma introdução à pesquisa qualitativa —um guia para iniciantes. Porto Alegre: Penso.

Flores, M. L. R. (2007). Movimento e complexidade na garantia do direito à Educação Infantil: um estudo sobre políticas públicas em Porto Alegre (19892004). Tese (Doutorado) - Universidade Federal do Rio Grande do Sul. Faculdade de Educação, Programa de Pós-Graduação em Educação. 
Research, Society and Development, v. 10, n. 15, e71101522604, 2021

(CC BY 4.0) | ISSN 2525-3409 | DOI: http://dx.doi.org/10.33448/rsd-v10i15.22604

https://lume.ufrgs.br/handle/10183/12217.

Franco, M. L. P. B. (2010). Diretrizes curriculares nacionais para a educação infantil. Análise de conteúdo. Brasília, $2^{\text {a }}$ edição: Liber Livro Editora, 2005. BRASIL. Secretaria de Educação Básica. Brasília: MEC, SEB.

Lemos, P. B. S., et. al. (2019). O conceito de paradigma em Thomas Kunh e Edgar Morin: similitudes e diferenças. Research, Society and Development, v. 8 , n. 10 , p. e078101321.

Marques, A. A. N. (2013). A ludicidade e o simbolismo na infância: um estudo hermenêutico em uma brinquedoteca escolar do município de São Luís/MA. Dissertação (Mestrado em Educação) - Universidade Federal do Maranhão. https://tedebc.ufma.br/jspui/handle/tede/tede/242.

Moraes, M. C. (2018). Transdisciplinaridade, criatividade e educação: fundamentos ontológicos e epistemológicos. Papirus Editora.

Morin, E. (2003). Da necessidade de um pensamento complexo. Representação e complexidade. Rio de Janeiro: Garamond, p. 69-77.

Morin, E. (2017). A cabeça bem-feita: repensar a reforma, reformar o pensamento. Rio de Janeiro, Bertrand Brasil.

Morin, E. (2020). É hora de mudarmos de via as lições do coronavírus. Rio de Janeiro Bertrand Brasil.

Nascimento, B. S. F. (2017). (Boas) práticas na creche: miradas emergentes sobre a criança e a infância. Tese (Doutorado) - Universidade Metodista de São Paulo. http://tede.metodista.br/jspui/handle/tede/1677.

Oliveira, M. P. S. (2010). Estudos da relação entre fromação docente e desenvolvimento do pensamento: redimensionando o olhares. Dissertação (Mestrado em Educação) - Universidade Federal do Rio Grande do Norte. https://repositorio.ufrn.br/jspui/handle/123456789/14377.

Pereira, B. G. (2014). Professores em formação inicial no gênero relatório de estágio supervisionado: um estudo em licenciaturas paraenses. Dissertação (Mestrado em Letras: ensino de Língua e Literatura) - Universidade Federal do Tocantins, Programa de Pós-Graduação em Letras: ensino de Língua e Literatura. http://repositorio.uft.edu.br/handle/11612/591.

Pinheiro, E. O. (2011). Dançando com gatos e passáros: O movimento ecossistêmico da ludopoiese na educação infantil. Tese (Doutorado em Educação) Universidade Federal do Rio Grande do Norte. https://repositorio.ufrn.br/jspui/handle/123456789/14442.

Rodrigues, J. S. M., \& Boer, N. (2019). Da epistemologia à prática docente na educação infantil: relato de uma sequência didática. Research, Society and Development, v. 8, n. 6, p. e186969.

Romanowski, J. P., \& Ens, R. T. (2006). As pesquisas denominadas do tipo "estado da arte" em educação. Revista diálogo educacional, v. 6, n. 19, p. $37-50$.

Souza, M. F. (2016). Além da escola: reflexões teórico-metodológicas com base na análise de práticas educativas alternativas descobertas em áreas rurais da região de São Carlos S.P. Tese (Doutorado) - Universidade Estadual Paulista "Júlio de Mesquita Filho". https://repositorio.unesp.br/handle/11449/137958.

Toledo, M. L. P. B. (2010). Children's relations and conceptions with/of nature: Rio de Janeiro. Dissertação (Mestrado) - Pontifícia Universidade Católica do Rio de Janeiro - PUC-Rio. https://www.maxwell.vrac.puc-rio.br/colecao.php?strSecao=resultado\&nrSeq=15793@ 1/https://www.maxwell.vrac.pucrio.br/Busca_etds.php?strSecao=resultado\&nrSeq=15793@2\#. 